\title{
mRNA expression profiles of calmodulin and liver receptor homolog-1 genes in chickens
}

\author{
Z.-C. Zhang, L.-H. Xiao, Y. Wang, S.-Y. Chen, Z.-Q. Yang, X.-L. Zhao, \\ Q. Zhu and Y.-P. Liu
}

College of Animal Science and Technology, Sichuan Agricultural University, Ya'an, Sichuan, China

Corresponding author: Q. Zhu

E-mail: Zhuqing5959@163.com

Genet. Mol. Res. 11 (3): 3482-3489 (2012)

Received October 7, 2011

Accepted March 2, 2012

Published September 26, 2012

DOI http://dx.doi.org/10.4238/2012.September.26.3

\begin{abstract}
Calmodulin (CALM), a calcium-binding protein, is expressed in the hypothalamic-pituitary-gonadal axis; it plays a pivotal role in the reproductive system by regulating gonadotropin-releasing hormone signaling. Downstream of hypothalamic-pituitary-gonadal signaling pathways, liver receptor homolog-1 (LRH-1) is involved in female gonadal hormone synthesis. In the chicken, although the two genes are known to be associated with reproductive traits, the interaction between gonadotropins and gonadal steroids remains unclear. We used quantitative real-time PCR to quantify the tissular (hypothalamus, pituitary, ovary, liver, kidney, oviduct, heart) and ontogenetic (12, 18, 32, and 45 weeks) mRNA expression profiles of CALM and $L R H-1$ in Erlang Mountainous chickens to determine their roles in the endocrine control of fertility, and compared these profiles with expression in Roman chickens. We found that the relative expressions of CALM and $L R H-1$ genes had the highest levels in the pituitary and ovary at 32 weeks. The expression level of CALM mRNA in the pituitary of Roman chickens was significantly higher than that in Erlang Mountainous chickens at 32 and 45 weeks, while the $L R H-1$ transcript level in the ovaries of Roman chickens was significantly lower than that of Erlang Mountainous chickens at 32 and 45 weeks. In summary, the transcript
\end{abstract}


levels of $C A L M$ and $L R H-1$ genes are associated with chicken reproductive traits; in addition, we found that the CALM gene is the key regulator in the hypothalamic-pituitary-gonadal signaling network.

Key words: Chicken; CALM; LRH-1; Quantitative real-time PCR

\section{INTRODUCTION}

Because the reproductive trait of chicken has high economic importance in the layer and breeding chicken industry, even a slight improvement in fertility ability have received considerable attention for breeders, geneticists, and farmers in recent years. Generally, female fertility requires normal ovarian follicular growth and ovulation, which depends on different hormones and growth factors in the follicular fluid and bi-directional communication between the oocyte and granulosa cells (Semiz and Evirgen, 2009). Several hormones and factors participate in the hypothalamic-pituitary-gonadal (HPG) signaling pathway, and they can be divided into 2 types by their biochemical characteristics, i.e., gonadotropins and gonadal steroids. Accordingly, candidate genes related to the gonadotropins and gonadal steroids can be defined, such as GHR, GnRHR, IGF-1, ESR, PRL, PRLR, and FSHR (Sharp et al., 1992; Contijoch et al., 1993; Linville et al., 2001; Sun et al., 2001; Gershon et al., 2007). Further studies are necessary to identify the key regulator of the HPG axis. In this study, we selected candidate genes on the basis of the knowledge obtained from other animal models and tested whether the relative expression levels of these genes are associated with reproductive performance in chicken.

Calmodulin (CALM) is the primary receptor protein of calcium $\left(\mathrm{Ca}^{2+}\right)$, and $\mathrm{Ca}^{2+}$ is a ubiquitous intracellular messenger responsible for controlling numerous cellular processes (Sun et al., 2001). CALM may play a critical role in specifically linking $\mathrm{Ca}^{2+}$ flux with extracellular signal-regulated protein kinase (ERK) activation within the gonadotropin-releasing hormone (GnRH) signaling pathway (Roberson et al., 2005). Further studies demonstrated that the frequency of the calcium pulse signal can differentially regulate $\alpha, \mathrm{LH} \beta$, and FSH $\beta$ transcriptional activity and mRNA expression (Haisenleder et al., 2003a,b). Therefore, $\mathrm{Ca}^{2+} /$ CALM may play a pivotal role in the GnRH signal pathway. The expression profile of CALM can reflect the activity of GnRH in the anterior pituitary and its involvement in the production and secretion of luteinizing hormone (LH) and follicle-stimulating hormone (FSH).

In ovary, the 2 main female hormones, $17 \beta$-estradiol and progesterone, have been characterized as steroid hormones that are directly involved in follicular growth and ovulation (Roberson et al., 2005). Mice null for cytochrome P450 aromatase (Cyp19) exhibit arrested follicular growth (Fisher et al., 1998), and enhanced estradiol action can reverse the ovulatory block (Gershon et al., 2007). $L R H-1$ belongs to the NR5A subfamily of nuclear receptors (Boerboom et al., 2000). In recent studies, it has became increasingly evident that $L R H-1$ plays a critical role in regulating steroidogenesis, female gonadal hormone synthesis, and sex determination (Roberson et al., 2005; Mueller et al., 2006). Furthermore, $L R H-1$ was reported to participate in ovarian follicular development by serving as a critical regulator of multiple mechanisms essential for the maturation of ovarian follicles and ovulation (Roberson et al., 2005).

Analysis of variation in gene expression would enable the study of the different reproductive performances (Cheung and Spielman, 2002). Using quantitative PCR (qPCR), we confirmed that the transcript abundance of the 2 candidate genes are associated with reproduction traits and that CALM is key regulator in the HPG signaling network. 


\section{MATERIAL AND METHODS}

\section{Birds}

One hundred and twenty birds representing 2 breeds, namely, Erlang Mountainous chicken (EM, $\mathrm{N}=80)$ and Roman hens $(\mathrm{R}, \mathrm{N}=40)$, were used in this study. The former is a Chinese indigenous chicken breed, while the latter is a commercial laying line. All birds were housed on the deep-litter bedding and were transferred to the growing pens at the age of 7 weeks. Birds had access to feed (commercial con-soybean diets meeting the National Research Council's [NRC] requirements) and water ad libitum. Chickens at 4 developmental stages (12, 18,32 , and 45 weeks) were randomly selected and raised under the same conditions on an experimental farm for poultry breeding at the Sichuan Agricultural University (Ya'an, China). Tissue samples (including those from the hypothalamus, pituitary, ovary, liver, kidney, oviduct, and heart) from EM $(N=20 /$ stage $)$ and $R(N=10 /$ stage $)$ chickens were collected at each time point. Fresh tissues were identified, excised, immediately frozen in liquid nitrogen, and stored at $-80^{\circ} \mathrm{C}$ until mRNA was isolated.

\section{RNA isolation and cDNA synthesis}

Total RNA was isolated from the hypothalamus, pituitary, ovary, liver, and oviduct tissues by using the Trizol reagent (Invitrogen) according to manufacturer instructions. The quality of RNA was determined by the $\mathrm{A}_{260 / 280}$ absorbance ratio (1.6-1.8) and the integrity of the $18 \mathrm{~S}$ and $28 \mathrm{~S}$ rRNA bands on $1 \%$ agarose gel. Isolated RNAs were treated with $8 \mu \mathrm{L}$ DNase (TakaRa Biotechnology Co. Ltd., Dalian, China) for $20 \mathrm{~min}$ at $37^{\circ} \mathrm{C}$ and stored at $-80^{\circ} \mathrm{C}$. The cDNA was synthesized using the ImProm-II Reverse Transcription System (TakaRa Biotechnology Co. Ltd.) according to manufacturer instructions. The reaction was performed in a volume of $10 \mu \mathrm{L}$ containing $5 \mathrm{X}$ PrimerScript buffer, $10 \mathrm{mM}$ of each dNTP, $40 \mathrm{U} / \mu \mathrm{L}$ RNase inhibitor, and $2.5 \mu \mathrm{M}$ oligo-dT primer. Reverse transcription was maintained at $30^{\circ} \mathrm{C}$ for $10 \mathrm{~min}, 45^{\circ} \mathrm{C}$ for $25 \mathrm{~min}$, and $99^{\circ} \mathrm{C}$ for $5 \mathrm{~min}$; it was stopped with incubation at $4^{\circ} \mathrm{C}$ for $5 \mathrm{~min}$, and the samples were stored at $-20^{\circ} \mathrm{C}$.

\section{Real-time qPCR (RT-PCR) assay for $C A L M$ and $L R H-1$}

Total RNA extraction and reverse transcription were performed as described above. According to the mRNA sequence of chicken CALM and $L R H-1$ recorded in GenBank (accession No. NM_205005.1 and NM_205078.1), gene-specific primers were designed by using Oligo 6.0 (Table 1 ) and the housekeeping gene $\beta$-actin was used as the reference. RT-PCR assays were carried out by using iQ5 real-time PCR thermal cycle instrument (Bio-Rad, USA). RT-PCR amplification was performed in $20 \mu \mathrm{L}$ of the reaction mixture containing $2 \mu \mathrm{L}$ cDNA sample, $10 \mu \mathrm{L}$ SYBR Premix Ex TaqTM 2X (TakaRa Biotechnology Co. Ltd.), $0.8 \mu \mathrm{L}$ of each

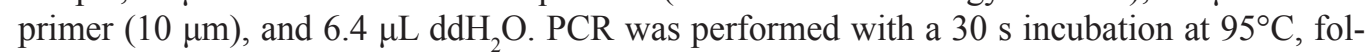
lowed by denaturation at $94^{\circ} \mathrm{C}$ for $5 \mathrm{~s}$, annealing at $52.5^{\circ} \mathrm{C}$ for $30 \mathrm{~s}$, and extension at $72^{\circ} \mathrm{C}$ for $50 \mathrm{~s}$ for 40 cycles. In order to check for non-specific amplification, after the completion of the PCR, melting curve analysis was also performed. The melting protocol consisted of $1 \mathrm{~min}$ at $95^{\circ} \mathrm{C}, 1 \mathrm{~min}$ at $55^{\circ} \mathrm{C}$, and $30 \mathrm{~s}$ at $55^{\circ} \mathrm{C}$, with 81 cycles in total. 
Table 1. Primers for quantitative real-time PCR of $\beta$-actin, CALM and $L R H-1$ genes.

\begin{tabular}{|c|c|c|c|c|c|}
\hline Gene & Sequences of primer pairs $\left(5^{\prime}-3^{\prime}\right)$ & Amplicon size (bp) & $\operatorname{Tm}\left({ }^{\circ} \mathrm{C}\right)$ & Optimal $\mathrm{Ta}\left({ }^{\circ} \mathrm{C}\right)$ & GenBank ID \\
\hline$\beta$-actin & $\begin{array}{l}\text { F: TGATGGAGTTGAAGGTGGTCTC } \\
\text { R: TCCCTGGAGAAGAGCTACGAG }\end{array}$ & 113 & 60.0 & 60.0 & NM_205518 \\
\hline CALM & $\begin{array}{l}\text { F: GAAGTAGACGCTGATGGCAATG } \\
\text { R: GTCAAACACACGGAACGCTTCT }\end{array}$ & 120 & 62.5 & 53.5 & NM_205005.1 \\
\hline LRH-1 & $\begin{array}{l}\text { F: GACTCAGGTGATCCAAGCTATGC } \\
\text { R: GAGAGGTTACAAAGGGGCTTCTG }\end{array}$ & 143 & 62.3 & 53.5 & NM_205078.1 \\
\hline
\end{tabular}

$\mathrm{Tm}=$ melting temperature. $\mathrm{Ta}=$ anneling temperature.

\section{Data analysis}

For each sample, the reactions were set up in triplicate to ensure the reproducibility of the results and were analyzed using the $2^{-\Delta \Delta \mathrm{Ct}}$ method described previously (Livak and Schmittgen, 2001). Data were represented as means \pm SD and were analyzed using the SAS 8.0 for Windows Software (SAS Institute Inc., Cary, NC, USA). The 2 breeds were compared for the expression levels of $C A L M$ and $L R H-1$ in each tissue sample at each stage by using one-way ANOVA. P value of $\leq 0.05$ was considered statistically significant.

\section{RESULTS}

\section{Expression profiling of chicken $C A L M$ and $L R H-1$}

The presence of non-specific PCR products and primer dimer artifacts was checked for by melting curve analysis. The amplification efficiency of $\beta$-actin, CALM, and $L R H-1$ genes were $96.3,91.9$, and $95.1 \%$, respectively, which were approximately within the expected theoretical values.

At 32 weeks, EM and R chicken were at the peak of egg production. Therefore, we selected the 32-week EM chicken populations for tissular studies of transcripts. Quantitative PCR analysis showed that $C A L M$ was expressed in all 7 chicken tissues, with the highest levels in the pituitary and hypothalamus, followed by the heart, liver, kidney, ovary, and the oviduct, in that order (Figure 1A). Then, we selected the pituitary, which had the highest expression level in the ontogenetic studies. The accumulation of the transcripts indicated that the abundances of the genes differed in the different stages. In the pituitary, CALM had the highest expression at 32 weeks and the lowest, at 45 weeks $(\mathrm{P} \leq 0.05$; Figure $2 \mathrm{~A})$. In addition, as shown in Figure $1 \mathrm{~B}$, we found that at 32 weeks, the expression level of $L R H-1$ was high in the ovary, liver, and heart, but low in the other tissues. Further, $L R H-1$ expression in the ovary was the highest at 32 weeks and the lowest at 18 weeks $(\mathrm{P} \leq 0.05)$ (Figure 2B).

\section{Comparison of gene expression levels between the $\mathrm{R}$ and $\mathrm{EM}$ chicken}

To further determine the key regulator gene, we analyzed the expression levels of CALM and $L R H-1$ in the 2 chicken populations. Figures $3 \mathrm{~A}$ and B present the mRNA expression levels of CALM and $L R H-1$ in EM and R birds at 32 and 45 weeks, respectively. The expression level of $C A L M$ mRNA in R chicken was higher than that in EM chicken at 32 and 45 weeks $(\mathrm{P} \leq 0.05)$, while the $L R H-1$ transcripts of $\mathrm{R}$ was lower than that of EM chicken at 32 and 45 weeks $(\mathrm{P} \leq 0.05)$. 
A

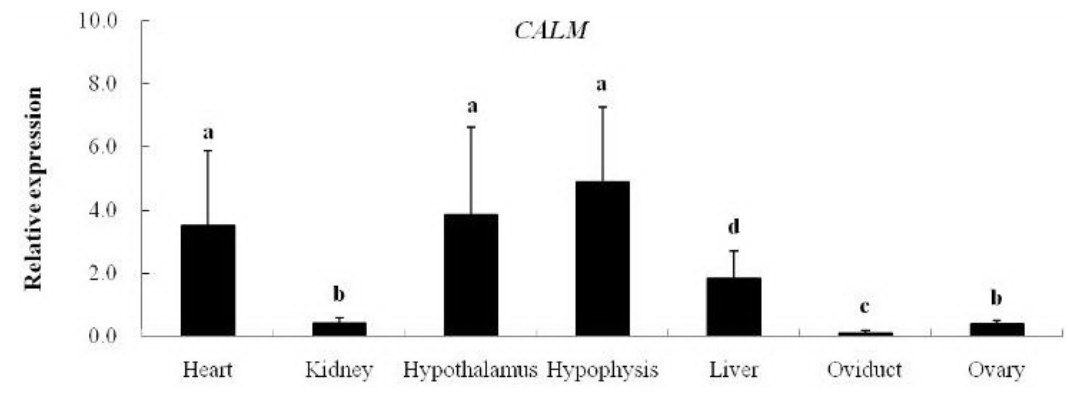

B

$L R H-1$

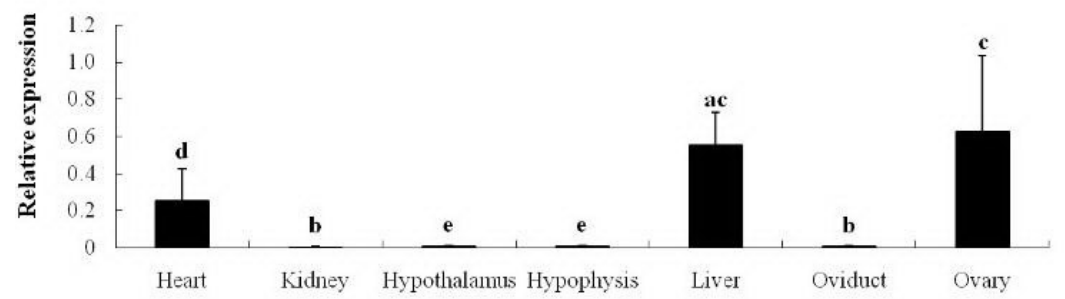

Figure 1. Relative mRNA expression level in different tissues from Erlang Mountainous chicken $(\mathrm{N}=20)$ at growth point (32 weeks) when hens were in high egg-production peak. All expression data were normalized with $\beta$-actin mRNA in each tissue and are reported as means \pm SD. Different letters above the columns indicate significant differences $(\mathrm{P} \leq 0.05)$. A. Relative mRNA of calmodulin $(C A L M)$ level in different tissues. B. Relative mRNA of liver receptor homolog-1 (LRH-1) level in different tissues.

A

$C A L M$

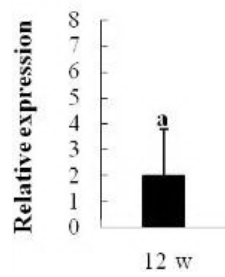

B

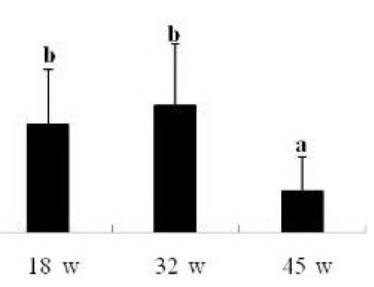

LRH -1

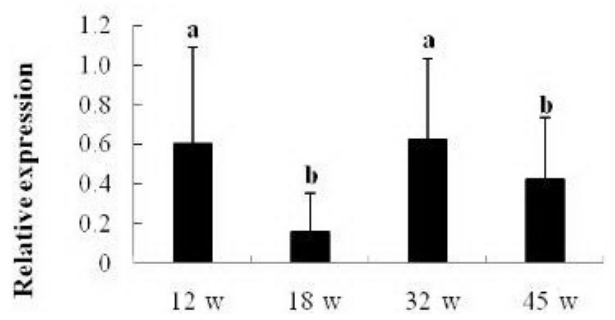

Figure 2. Relative mRNA expression levels at different stages from Erlang Mountainous chicken $(\mathrm{N}=20)$ in predominant tissue. Different letters above the columns indicate significant differences $(\mathrm{P} \leq 0.05)$. A. Relative mRNA of calmodulin $(C A L M)$ level in pituitary at different stages. B. Relative mRNA of liver receptor homolog-1 $(L R H-1)$ level in ovary at different stages. $\mathrm{w}=$ weeks. 
A $C A L M$

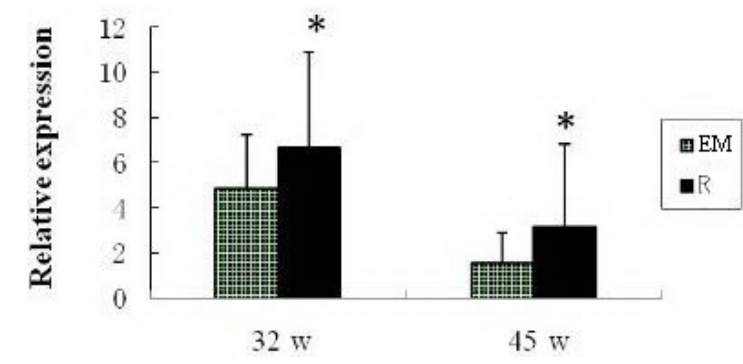

B

$L R H-1$

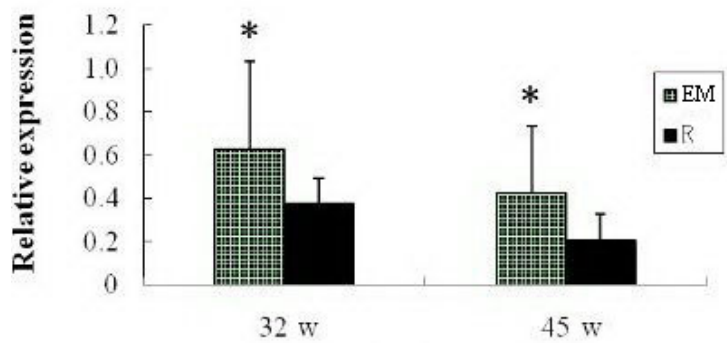

Figure 3. Relative expression levels between two different breeds at 32 and 45 weeks (w). Asterisks above the columns indicate significant differences $(\mathrm{P} \leq 0.05)$. A. Relative mRNA expression level of the calmodulin $(C A L M)$ gene. B. Relative mRNA expression level of the liver receptor homolog-1 ( $L R H-1)$ gene. EM=Erlang Mountainous chicken. $\mathrm{R}=$ Roman hens.

\section{DISCUSSION}

Because we limited our study to reproductive traits, it primarily involved a targeted assessment of candidate gene expression in hens. At 32 weeks, when the EM chickens are at the peak of egg production, we quantified the relative expressions in 7 tissue samples. CALM was expressed in all tissues, with the highest level in the pituitary and hypothalamus, which is consistent with Kahl's view (Kahl and Means, 2003). CALM is responsible for controlling numerous cellular processes, and studies indicate that CALM and its dependent kinase (CAMK) regulate the intracellular signaling cascades triggered by GnRH (Burger et al., 2008). Additionally, we found that the expression level of $L R H-1$ was high in the ovary, liver, and heart, but very low in the other tissues. It provided evidence that $L R H-1$ mRNA was expressed in steroidogenic organs (Fayard et al., 2004; Kudo and Sutou, 2006).

Consistent with previous reports, our findings showed that CALM and $L R H-1$ are predominantly expressed in the pituitary and ovary. We monitored the relative expressions of CALM and $L R H-1$ in the predominant tissues of EM chicken at 4 stages $(12,18,32$, and 45 weeks). The obtained results indicated that both CALM and $L R H-1$ had the highest expression level at 32 weeks in the pituitary and ovary, respectively. In a previous study, a coordinated array of signals was attributed to the maturation of ovarian follicles, and for ovulation, go- 
nadotropins, and gonadal steroids, such as LH and progesterone, were reported to be important factors (Brännström et al., 2010). During the peak of egg production, these hormones and their receptors were in activated states. Studies in rats showed that the mRNA expression levels of receptors of GnRH, FSH, and LH were elevated in the follicular stages of the estrous cycle (Patsoula et al., 2001; Crawford et al., 2009). Therefore, our results supported the views that CALM and $L R H-1$ are associated with the synthesis of glycopeptides, gonadotropins, and steroid gonadal hormones in chicken; in other words, we confirmed that the 2 candidate genes are important regulators of HPG axis signaling. Notably, the mRNA expression levels of $C A L M$ and $L R H-1$ were elevated at the 32 weeks group; however, since CALM regulates the components upstream of the HPG signaling pathway, it is difficult to determine whether the variations in mRNA expression of $L R H-1$ were in response to the upregulation of CALM. In general, GnRH stimulates the synthesis and release of the pituitary gonadotropins LH and FSH, which in turn regulate the production of gonadal steroid hormones (Dunn et al., 2003). Thereafter, gonadal steroids act at the hypothalamus and/or pituitary levels to either positively or negatively influence LH and FSH synthesis and secretion; the control of hormone synthesis and secretion is complex, and the detailed molecular mechanism underlying them remains unclear. Therefore, we focused on comparing the expression profiles of the 2 genes in 2 breeds (EM and R) that have different genetic backgrounds.

The relative abundance of gene transcripts is significantly different between the 2 breeds: the expression level of CALM was 1.4-fold less and 2.1-fold less in EM chicken than in $\mathrm{R}$ chicken and the relative expression of $L R H-1$ was 1.6-fold higher and 2.0-fold higher in EM chicken than in R chicken at 32 and 45 weeks, respectively. These findings revealed that the differences of the reproductive traits between the R and EM chicken were mainly attributed to the upregulation of CALM in the former. Compared to $L R H-1, C A L M$ is a more important regulator in the HPG signaling network.

Certainly, we cannot ignore the important role of steroid hormones. In the intricate interplay between the components of the HPG axis, GnRH serves as the initiator of the cascade and CALM regulates the activity upstream of the signaling network. The synthesis of steroid hormones may involve some compensation pathways in addition to LRH-1, which is a pivotal regulator. Because of the complexity in biological signal systems (Weng et al., 1999), an understanding of the entire signaling network of the HPG axis is difficult to understand (Brännström et al., 2010); further studies based on a systems biology might facilitate the elucidation of this problem (Zhu and Zhao, 2007).

In summary, we confirmed that $C A L M$ expression is related to the pituitary's activities, and $L R H-1$, to the ovary and liver. The upregulation of CALM mRNA expression may be mainly related to production characteristics. Further studies will be essential to explore the entire signaling network about the interplay of the components of the HPG axis by a system biology approach.

\section{ACKNOWLEDGMENTS}

Research supported by the earmarked fund for Modern Agro-industry Technology Research System (\#CARS-41-K06), the Program for New Century Excellent Talents in University (\#NCET-10-0889), the Science Fund for Young Scholars in Sichuan Province (\#09ZQ 026-017, \#09ZZ021). 


\section{REFERENCES}

Boerboom D, Pilon N, Behdjani R, Silversides DW, et al. (2000). Expression and regulation of transcripts encoding two members of the NR5A nuclear receptor subfamily of orphan nuclear receptors, steroidogenic factor-1 and NR5A2, in equine ovarian cells during the ovulatory process. Endocrinology 141: 4647-4656.

Brännström M, Lind AK and Dahm-Kähler P (2010). Ovulation: A molecular view. Reprod. Endocrinol. Infertil. 119-132.

Burger LL, Haisenleder DJ, Aylor KW and Marshall JC (2008). Regulation of intracellular signaling cascades by GNRH pulse frequency in the rat pituitary: roles for CaMK II, ERK, and JNK activation. Biol. Reprod. 79: 947-953.

Cheung VG and Spielman RS (2002). The genetics of variation in gene expression. Nat. Genet. 32: 522-525.

Contijoch AM, Malamed S, McDonald JK and Advis JP (1993). Neuropeptide Y regulation of LHRH release in the median eminence: immunocytochemical and physiological evidence in hens. Neuroendocrinology 57: 135-145.

Crawford JL, Heath DA, Haydon LJ, Thomson BP, et al. (2009). Gene expression and secretion of LH and FSH in relation to gene expression of GnRH receptors in the brushtail possum (Trichosurus vulpecula) demonstrates highly conserved mechanisms. Reproduction 137: 129-140.

Dunn IC, Lewis PD, Wilson PW and Sharp PJ (2003). Acceleration of maturation of FSH and LH responses to photostimulation in prepubertal domestic hens by oestrogen. Reproduction 126: 217-225.

Fayard E, Auwerx J and Schoonjans K (2004). LRH-1: an orphan nuclear receptor involved in development, metabolism and steroidogenesis. Trends Cell Biol. 14: 250-260.

Fisher CR, Graves KH, Parlow AF and Simpson ER (1998). Characterization of mice deficient in aromatase (ArKO) because of targeted disruption of the cyp19 gene. Proc. Natl. Acad. Sci. U. S. A. 95: 6965-6970.

Gershon E, Hourvitz A, Reikhav S, Maman E, et al. (2007). Low expression of COX-2, reduced cumulus expansion, and impaired ovulation in SULT1E1-deficient mice. FASEB J. 21: 1893-1901.

Haisenleder DJ, Ferris HA and Shupnik MA (2003a). The calcium component of gonadotropin-releasing hormonestimulated luteinizing hormone subunit gene transcription is mediated by calcium/calmodulin-dependent protein kinase type II. Endocrinology 144: 2409-2416.

Haisenleder DJ, Burger LL, Aylor KW, Dalkin AC, et al. (2003b). Gonadotropin-releasing hormone stimulation of gonadotropin subunit transcription: evidence for the involvement of calcium/calmodulin-dependent kinase II $(\mathrm{Ca} /$ CAMK II) activation in rat pituitaries. Endocrinology 144: 2768-2774.

Kahl CR and Means AR (2003). Regulation of cell cycle progression by calcium/calmodulin-dependent pathways. Endocr. Rev. 24: 719-736.

Kudo T and Sutou S (2006). Chicken $L R H-1$ gene is transcribed from multiple promoters in steroidogenic organs. Gene 367: 38-45.

Linville RC, Pomp D, Johnson RK and Rothschild MF (2001). Candidate gene analysis for loci affecting litter size and ovulation rate in swine. J. Anim. Sci. 79: 60-67.

Livak KJ and Schmittgen TD (2001). Analysis of relative gene expression data using real-time quantitative PCR and the $2^{-\Delta \Delta C t}$ Method. Methods 25: 402-408.

Mueller M, Cima I, Noti M, Fuhrer A, et al. (2006). The nuclear receptor $L R H-1$ critically regulates extra-adrenal glucocorticoid synthesis in the intestine. J. Exp. Med. 203: 2057-2062.

Patsoula E, Loutradis D, Drakakis P, Kallianidis K, et al. (2001). Expression of mRNA for the LH and FSH receptors in mouse oocytes and preimplantation embryos. Reproduction 121: 455-461.

Roberson MS, Bliss SP, Xie J, Navratil AM, et al. (2005). Gonadotropin-releasing hormone induction of extracellularsignal regulated kinase is blocked by inhibition of calmodulin. Mol. Endocrinol. 19: 2412-2423.

Semiz O and Evirgen O (2009). The effect of growth hormone on ovarian follicular response and oocyte nuclear maturation in young and aged mice. Acta Histochem. 111: 104-111.

Sharp PJ, Dunn IC and Cerolini S (1992). Neuroendocrine control of reduced persistence of egg-laying in domestic hens: evidence for the development of photorefractoriness. J. Reprod. Fertil. 94: 221-235.

Sun YM, Dunn IC, Baines E, Talbot RT, et al. (2001). Distribution and regulation by oestrogen of fully processed and variant transcripts of gonadotropin releasing hormone I and gonadotropin releasing hormone receptor mRNAs in the male chicken. J. Neuroendocrinol. 13: 37-49.

Weng G, Bhalla US and Iyengar R (1999). Complexity in biological signaling systems. Science 284: 92-96.

Zhu M and Zhao S (2007). Candidate gene identification approach: progress and challenges. Int. J. Biol. Sci. 3: 420-427. 